\title{
Anodized Edge-plane Pyrolytic Graphite for Electroanalysis of Pantoprazole in Tablet Dosage Forms and Human Urine Samples
}

\author{
Mojtaba Hadi* and Ali Ehsani \\ Department of Chemistry, Faculty of Sciences, University of Qom, Qom, Iran. \\ Received 21 January 2016, revised 24 February 2016, accepted 5 March 2016.
}

\begin{abstract}
Electroanalytical parameters of different graphitic carbon-based electrode materials were compared to select the best one for the pantoprazole electroanalysis. Such parameters include sensitivity, repeatability, residual background current, and signal-tobackground current ratio of the analytical response and such electrodes include conventional carbon-based electrodes such as glassy carbon (GC), carbon paste, edge-plane pyrolytic graphite (EPPG), and basal-plane pyrolytic graphite electrodes and film-coated modified GC electrodes with graphitic carbon-based materials such as carbon nanotube, nanographene, carbon black and graphite powder. The EPPG electrode, after applying a simple electrochemical anodization, showed more acceptable analytical performances compared with the other electrodes. Raman spectroscopy was employed to study the surface structural changes that occurred dring the anodic activation. Calibration plot with a good linearity was obtained in the concentration range of $0.2-25$ and $0.02-8.5 \mu \mathrm{M}$, and the detection limit was estimated to be 0.055 and $0.0041 \mu \mathrm{M}$ using cyclic voltammetry and differential pulse voltammetry techniques, respectively. Finally, the electrochemically activated EPPG electrode was used successfully for the determination of pantoprazole in tablet dosage forms and human urine samples with satisfactory results.
\end{abstract}

KEYWORDS

Edge-plane pyrolytic graphite, graphitic carbon-based electrodes, anodic activation, pantoprazole electroanalysis, nanographene, carbon nanotube.

\section{Introduction}

Pantoprazole (Scheme 1) is a proton pump inhibitor drug used to treat disorders of gastric acid hypersecretion, ulcer disease and gastroesophageal reflux disease. ${ }^{1}$

Analytical determination of pantoprazole in pharmaceutical formulations and in biological media is routinely based on chromatographic ${ }^{2-11}$ and spectroscopic methods. ${ }^{12-15}$ Considering the electro-oxidation ability of pantoprazole probably due to the presence of an amino group at the benzimidazole ring of its structure, ${ }^{16}$ developing voltammetric methods should be a better approach to its analytical determination because it is well known that these methods can overcome some of the problems associated to the chromatographic or spectroscopic methods. The latter methods always require expensive instruments and time-consuming sample preparation steps while the voltammetric methods provide advantages such as simplicity, low cost, far less expensive instrumentation, rapid analysis time, high sensitivity and portability.

In recent years, there have been extensive works focused on developing electroanalytical methods for the determination of drug dosage forms and drugs in biological fluids, many of which are based on redox reaction of a drug at the surface of solid electrode materials. ${ }^{17,18}$ Selecting the appropriate material as working electrode is perhaps primarily important that influences a successful analysis. Among different electrode materials, carbon-based graphitic materials are perhaps the most appropriate ones due to their relatively wide working potential window, low cost, high electrical conductivity, chemical inertness, low background current, and suitability for surface modification. ${ }^{19}$

* To whom correspondence should be addressed. E-mail: m.hadi@qom.ac.ir

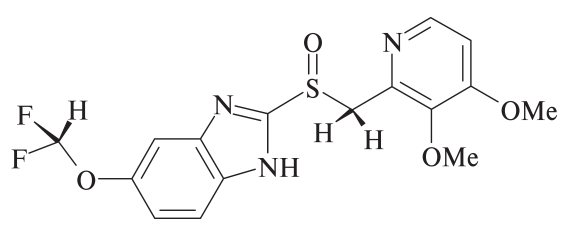

Scheme 1

Chemical structure of pantoprazole.

Particularly, in recent years, nanostructured graphitic carbon forms such as carbon nanotubes and nanographenes have attracted increasing attention as electrode materials for electroanalytical sensing applications owing to their excellent electron-transfer ability and large surface area. ${ }^{20,21}$ The electrochemistry of carbon-based graphitic materials has been well studied during the past few decades and it has been known that different forms of carbons, depending on their microstructural characteristics, show different electrochemical activities. ${ }^{19,22}$ Therefore, in order to achieve better analysis results, it seems to be essential to select the best choice among different available carbon-based materials.

In this paper, in attempt to achieve a highest possible sensitive and analytically reliable voltammetric method for the analysis of pantoprazole, the results of its electro-oxidation at different traditional and nanostructured graphitic carbon-based electrode materials are investigated and compared with each other. So far, direct electro-oxidation of pantoprazole at the carbonbased electrodes has been reported based on carbon paste $(\mathrm{CP})^{23}$ and glassy carbon $(\mathrm{GC})^{24,25}$ electrodes. Except carbonbased electrodes, hanging mercury drop (HMD) ${ }^{26,27}$ and chemi- 
cally modified electrodes ${ }^{28-32}$ have been also used for pantoprazole electroanalysis. At the first part of this paper, electrooxidation of pantoprazole at the $\mathrm{CP}, \mathrm{GC}$, edge-plane pyrolytic graphite (EPPG), basal-plane pyrolytic graphite (BPPG), and some nanostructured carbon-based materials such as CNTmodified GC, graphene oxide (GO)-modified GC, and carbon black (CB)-modified GC electrodes are comparatively evaluated . The best results, based on the analytical criteria, were obtained at the EPPG electrode after a simple and fast electrochemical pretreatment. Compared with the other electroanalytical methods reported either based on direct electro-oxidation at the carbon-based electrodes or based on applying chemically modified electrodes, the proposed method showed similar or better performance. In the last part of this paper, determination of pantoprazole at the electrochemically pretreated EPPG at trace level in pure, dosage forms, and in the biological samples (spiked urine samples) is presented.

\section{Experimental}

\subsection{Materials}

All chemicals were of analytical grade. Britton-Robinson buffer solutions (BRSs), $0.1 \mathrm{M}$, were prepared from phosphoric acid (85\%), boric acid, acetic acid and $\mathrm{KOH}$ (Merck). The standard pantoprazole (Sigma) solutions were prepared with the same buffer. Graphite powder (GP), <40 $\mu \mathrm{m}$, was purchased from Merck. Multi-walled carbon nanotube (CNT) (outside diameter 20-40 nm; length 1-2 $\mu \mathrm{m}$ ) was purchased from Io-Li-Tec, Germany. Graphene oxide (GO) (lateral lengths of graphene layers $0.5-3.0 \mu \mathrm{m}$; thicknesses $0.55-1.20 \mathrm{~nm}$ ) was obtained from Neutrino Company, Iran. CB powder (Grade N330 V3) was kindly donated by Iran Carbon Co. (Tehran, Iran).

\subsection{Apparatus}

Electrochemistry experiments were performed using a Sama 500 electroanalyzer system (Isfahan, Iran). A platinum plate was used as an auxiliary electrode and an $\mathrm{Ag} / \mathrm{AgCl}(3 \mathrm{M} \mathrm{KCl})$ was used as a reference electrode. The Raman spectra were recorded using a Bruker dispersive Raman microscope (SENTERRA, Germany) operating at laser wavenumber of $785 \mathrm{~nm}$.

\subsection{Carbon Working Electrodes}

Glassy carbon (GC) electrode (geometric surface area $3.14 \mathrm{~mm}^{2}$ ) was obtained from Azar Electrode Co. (Iran) and was prepared by polishing with slurry of $0.05 \mu \mathrm{m}$ alumina in distilled water on a polishing cloth. Carbon paste $(\mathrm{CP})$ was prepared by mixing of $0.7 \mathrm{~g}$ of GP and $0.3 \mathrm{~g}$ of mineral oil in a mortar. A portion of the resulting paste was then packed tightly into a Teflon tube. The paste surface (geometric surface area $10.75 \mathrm{~mm}^{2}$ ) was smoothed on a weighing paper prior to use. Edge-plane pyrolytic graphite (EPPG) and basal-plane pyrolytic graphite (BPPG) electrodes were prepared by machining a pyrolytic graphite pieces into discs (geometric surface area $7.58 \mathrm{~mm}^{2}$ ) with the faces parallel with the edge-plane or basal-plane. ${ }^{33,34}$ The EPPG electrode was first polished on emery polishing papers and then on a polishing cloth with slurry of alumina $(0.05 \mu \mathrm{m})$ in distilled water. The surface of BPPG was renewed by pressing a strip of Sellotape ${ }^{\circledR}$ onto the electrode surface and then peeling away the top few layers of graphite. ${ }^{33,34} \mathrm{GO}, \mathrm{CNT}, \mathrm{CB}$ and GP were cast onto the GC electrode surfaces. They were first dispersed in $\mathrm{N}, \mathrm{N}$-dimethylformamide $\left(1 \mathrm{mg} \mathrm{mL}^{-1}\right)$ by an ultrasonic bath. $2 \mu \mathrm{L}$ of the suspensions were then placed onto the GC electrode surfaces with a micro-pipette. Their solvent was then allowed to evaporate by an infra-red lamp, thereby creating a randomly distributed carbon film on the GC surface.

\subsection{Electrochemical Pretreatment}

Anodic activation of the EPPG electrodes was performed by applying a constant anodization potential of $1.8 \mathrm{~V}$ (vs. Ag/AgCl) for $300 \mathrm{~s}$ in $0.1 \mathrm{M}$ BRS ( $\mathrm{pH}$ 5).

The GO-modified GC electrode was reduced electrochemically by applying $-1.0 \mathrm{~V}$ (vs. $\mathrm{Ag} / \mathrm{AgCl}$ ) for $60 \mathrm{~s}$ in $0.1 \mathrm{MBRS}(\mathrm{pH} 5)$. It was designated as ErGO-modified GC electrode.

\section{Results and Discussion}

\subsection{Electro-oxidation of Pantoprazole at Different Graphitic} Carbon-based Electrode Materials

Figures 1-5 represent typical cyclic voltammograms recorded for $15 \mu \mathrm{M}$ of pantoprazole in $0.1 \mathrm{M}$ BRS ( $\mathrm{pH}$ 5) at different conventional and nanostructured graphitic carbon-based electrodes and the results such as peak current $\left(I_{\mathrm{p}}\right)$, peak potential $\left(E_{\mathrm{p}}\right)$, sensitivity, and signal-to-background current $(\mathrm{S} / \mathrm{B})$ ratio are summarized in Table 1, for ease of comparison.

\subsubsection{Sensitivity}

The results in Fig. 1, that shows the overlaid voltammograms obtained at the EPPG and BPPG electrodes, indicate that the electro-oxidation of pantoprazole is significantly influenced by the surface density of electrochemically active graphitic edge-plane sites. It has been well documented that the electron transfer kinetics at the edge-plane sites is significantly higher than that at the basal-plane sites. ${ }^{19,22,34}$ Among different traditional graphitic carbon-based materials, EPPG is known as a form of carbon whose surface microstructure is almost wholly composed of edge-planes ${ }^{33,34}$ (schematically illustrated in Fig. 6). As expected, this electrode also shows more electron transfer activity compared with the GC and CP electrodes (Fig. 1), whose surfaces partly are composed of electrochemically inert basalplanes. $^{22}$

Figure 2 shows the voltammograms obtained at the EPPG before and after anodic activation. Since the electrochemical anodization can be applied quickly and simply in the supporting electrolyte solution, the effects of anodic activation on the electrode response were also investigated as the simplicity and

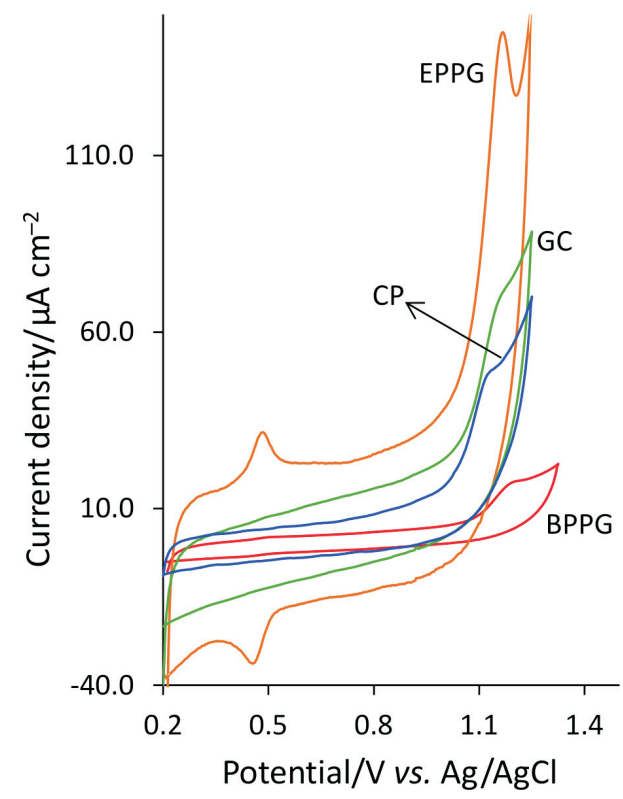

Figure 1 Cyclic voltammetric responses of the carbon electrodes in $15 \mu \mathrm{M}$ pantoprazole in $0.1 \mathrm{M} \mathrm{BRS}\left(\mathrm{pH}\right.$ ) at $100 \mathrm{mV} \mathrm{s}^{-1}$. The current values are normalized by the geometric surface area of the electrodes, mentioned in the experimental section. 


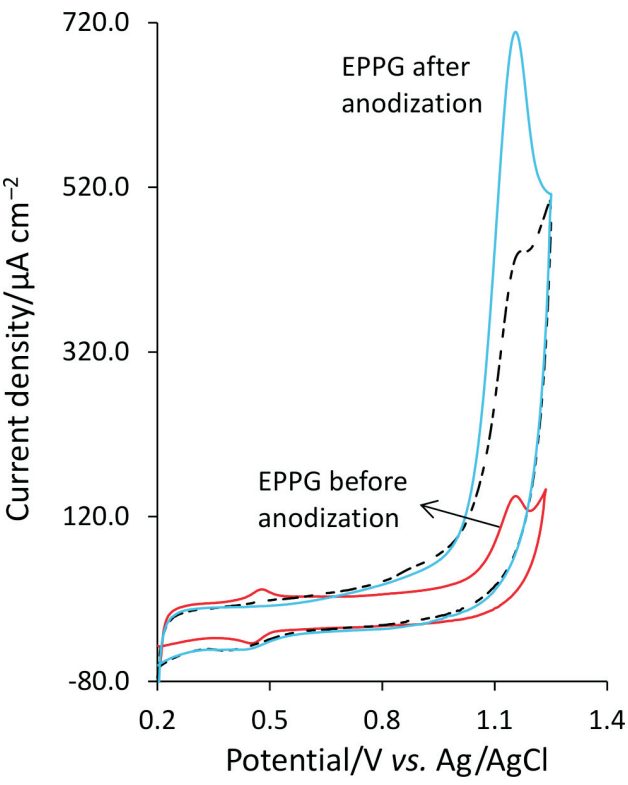

Figure 2 Cyclic voltammetric responses of the EPPG electrode in $15 \mu \mathrm{M}$ pantoprazole in 0.1 M BRS ( $\mathrm{pH}$ 5) before and after (solid-line voltammograms) anodic activation. The dashed-line voltammogram is recorded at anodized EPPG electrode in 0.1 M BRS (pH 5) after dipping in15 $\mu \mathrm{M}$ pantoprazole solution. Scan rate $100 \mathrm{mV} \mathrm{s}^{-1}$.

rapidity of the method are among the main goals of this study. By deliberately increasing the amount of surface oxides at the graphitic carbon-based electrodes, the electron transfer kinetics of many biologically important compounds has shown appreciable increases. ${ }^{19,22,34}$ From Fig. 2 and Table 1, it is clear that electrochemical anodization has very significant influence on the electrode response, about ten folds increase in $I_{\mathrm{p}}$. This may be attributed to the adsorption/accumulation of pantoprazole molecules from the solution phase on the anodized electrode surface perhaps due to interactions such as hydrogen bonding between generated surface oxides and amine groups of pantoprazole molecules or electrostatic adsorption between some positively charged amine groups of pantoprazole molecules and anionic surface oxygen functionalities. The voltammogram recorded in the supporting electrolyte solution at the anodized EPPG electrode after only dipping in the pantoprazole solution $(15 \mu \mathrm{M})$ for $180 \mathrm{~s}$, removing from the solution, and washing with distilled water for $30 \mathrm{~s}$ (Fig. 2, dashed-line voltammogram) shows only a slightly lower $I_{\mathrm{p}}$ value than that recorded in the pantoprazole solution, which is a good indication of the adsorption contribution to the electrode process.

In Fig. 3, the same voltammograms obtained at the anodized EPPG electrode is also overlaid on that obtained at the CNT-modified GC electrode. These electrodes show nearly a

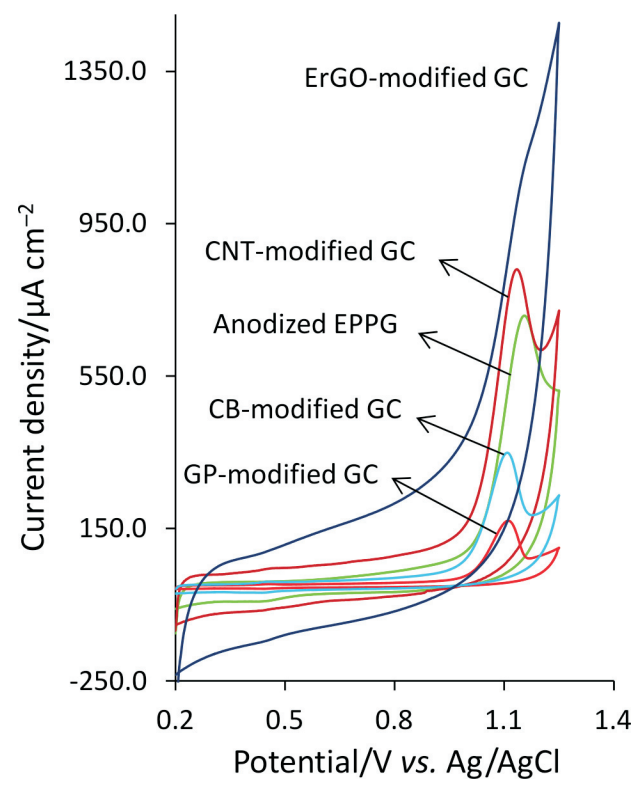

Figure 3 Cyclic voltammetric responses of the carbon electrodes in $15 \mu \mathrm{M}$ pantoprazole in $0.1 \mathrm{M} \mathrm{BRS} \mathrm{(pH} \mathrm{5)} \mathrm{at} 100 \mathrm{mV} \mathrm{s}^{-1}$. The current values are normalized by the geometric surface area of the electrodes, mentioned in the experimental section.

similar level of $I_{\mathrm{p}}$ and $E_{\mathrm{p}}$ values (Fig. 3 and Table 1) (it should be noted that the $I_{\mathrm{p}}$ values are reported after their corresponding background current subtraction). A high density of the edge sites occurred at the open ends of nanotubes or defects along their side walls in CNT along with a large surface area of the CNT film may provide a high ability to this material to promote the electron-transfer reaction..$^{21}$ In Fig. 3, the voltammograms obtained at the ErGO-modified GC is also compared with that obtained at the CNT-modified GC and anodized EPPG electrodes.

In recent years, nanographene materials have attracted enormous interest for use as electrode in electrochemical applications. ${ }^{20,21}$ Their fundamental electrochemical properties have been also investigated so that for some benchmark redox couples such as $\left[\mathrm{Fe}(\mathrm{CN})_{6}\right]^{3-4-36}$ and $\left[\mathrm{Ru}\left(\mathrm{NH}_{3}\right)_{6}\right]^{3 / 2}{ }^{37}$ they show fast electron transfer kinetics. From Fig. 3 and Table 1, ErGO shows only a slightly lower $I_{p}$ value than that observed at the CNT-modified GC and anodized EPPG electrodes. However, a high residual current and a broad and not well-defined peak (Fig. 3) are the main drawbacks that cause this electrode to be unacceptable for pantoprazole electroanalysis.

The voltammograms obtained at the CB-modified and GP-modified GC electrodes are also presented in Fig. 3 for comparison. In the presence of the benchmark redox systems such as $\left[\mathrm{Fe}(\mathrm{CN})_{6}\right]^{3-/ 4},\left[\mathrm{Ru}\left(\mathrm{NH}_{3}\right)_{6}\right]^{3 / 2}$ and ascorbic acid, CB has

Table 1 Comparison of analytical data at different electrodes.

\begin{tabular}{|c|c|c|c|}
\hline Electrode & Sensitivity $/ \mu \mathrm{A} \mathrm{cm}^{-2} \mu \mathrm{M}^{-1}$ a & $\mathrm{Ep} / \mathrm{V}$ vs. $\mathrm{Ag} / \mathrm{AgCl}^{\mathrm{a}}$ & $\mathrm{S} / \mathrm{B}$ ratio $^{\mathrm{a}}$ \\
\hline EPPG & 5.27 & 1.12 & 1.2 \\
\hline BPPG & 0.91 & 1.18 & 4.3 \\
\hline GC & 2.16 & 1.16 & 0.77 \\
\hline $\mathrm{CP}$ & 1.14 & 1.15 & 0.53 \\
\hline CNT-modified GC & 39.88 & 1.13 & 2.59 \\
\hline ErGO-modified GC electrode & 33.44 & 1.15 & 0.55 \\
\hline CB-modified GC electrode & 23.55 & 1.2 & 3.19 \\
\hline GP-modified GC electrode & 13.93 & 1.2 & 2.76 \\
\hline Anodized EPPG & 40.45 & 1.12 & 5.88 \\
\hline
\end{tabular}

\footnotetext{
${ }^{a}$ The values represent the mean value of at least three replicate determinations.
} 
shown fast, reversible, and a comparable electrochemical performance to that of nanographene. ${ }^{38}$ For GP, for the electrooxidation of some biologically important compounds, a similar or a higher level of electrochemical activity has been observed compared with multi-walled $\mathrm{CNT}^{39}$ or nanographenes. ${ }^{40}$ As can be seen from Fig. 3 and Table 1, none of these electrodes (CB-modified and GM-modified GC electrodes) showed any improvement in their responses over the other electrode studied. In overall, the anodized EPPG electrode produces the highest response sensitivity and after that, by a slight difference, CNTmodified GC electrode shows the highest sensitivity.

\subsubsection{Residual Background Current and Signal-to-Background Current (S/B) Ratio}

The background voltammograms obtained in the supporting electrolyte solution at different carbon electrodes are depicted in Fig. 4.

As also mentioned in the previous section, the ErGO-modified GC shows the highest level of residual current and after that, CNT-modified GC electrode, anodized EPPG and CB-modified GC electrodes show approximately a same level of residual current. As can be seen from Table 1, among the other electrodes studied, the anodized EPPG produces the highest value of $\mathrm{S} / \mathrm{B}$ ratios. This is because of a high faradaic current together with a relatively low residual current at this electrode.

\subsubsection{Repeatability}

As reproducible results are very crucial in sensing applications, the reproducibility of the response was also evaluated. Since the anodized EPPG, CNT-modified GC and CB-modified GC electrodes exhibit more acceptable results in terms of S/B ratio, residual current and sensitivity, only the response repeatability of these electrodes was examined by repeating a cyclic voltammetry $(\mathrm{CV})$ scan 7 times while the solution was mixed between consecutive runs for $3 \mathrm{~min}$ and allowed to stand for $30 \mathrm{~s}$ without mixing before each scan. The relative standard deviation (RSD) of the $I_{\mathrm{p}}$ for the anodized EPPG, CNT-modified GC and CB-modified GC electrodes were, in the given order, $4.38 \%$, $11.42 \%$ and $8.52 \%$. Fig. 5, as an example, shows the first, third and seventh voltammograms recorded at the anodized EPPG and CNT-modified GC electrodes. The lower value of RSD $(4.3 \%)$ obtained at the anodized EPPG electrode indicates

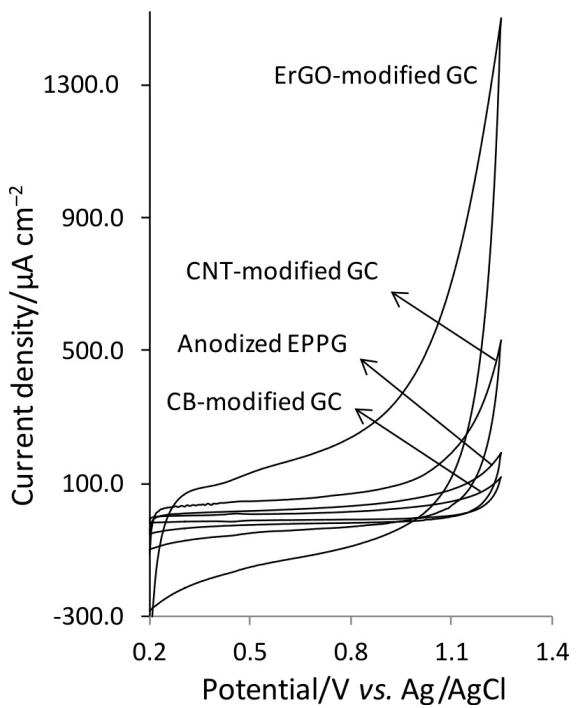

Figure 4 Comparison of background cyclic voltammetric responses. The voltammograms are recorded in the supporting electrolyte solution of $0.1 \mathrm{M}$ BRS (pH 5). Scan rate $100 \mathrm{mV} \mathrm{s}^{-1}$. higher stability and repeatability of its signal. This may be attributed to the high density of edge planes on its surface that reduces electrode inactivation by surface adsorption of the oxidation products. ${ }^{34}$ Also, compared with the porous nature of the solvent casting-fabricated $\mathrm{CNT}$ and $\mathrm{CB}$ films, a relatively smoother surface of the anodized EPPG electrode allowed adsorbed reaction products to be cleaned more easily by washing with streaming solution.

\subsubsection{Selecting the Best Choice among the Carbon-based Electrodes}

In general, it may be concluded from the results in Figs. 1-5, and Table 1 that the EPPG after anodic activation is a more suitable electrode material for pantoprazole sensing. The EPPG electrode also has some other advantages over CNT or GO such as lower cost and ease of electrode preparation, as in each time after the electrode inactivation, the former can be easily reactivated by a simple mechanical polishing while the latter electrodes need to be fabricated afresh by time-consuming solvent-casting method.

\subsection{Studying the Microstructural Surface Characteristics of the EPPG Before and After Anodization}

A schematic representation of the pyrolytic graphite structure is shown in Fig. 6. The bulk of pyrolytic graphite consists of stacked graphitic crystallites. Due to the regular arrangement of these crystallites, pyrolytic graphite shows two distinct surfaces, one along (basal-plane surface) and the other orthogonally (edge-plane surface) to the direction of graphitic sheets. ${ }^{33,34}$ Fig. 6 also shows the first-order Raman spectra of the pyrolytic graphite obtained from the basal-plane and edge-plane of both surface. It has been well-known that the Raman spectra of carbon-based electrode materials reflect their surface microstructures very sensitively. ${ }^{22}$ As it is clear from Fig. 6, the analysis performed on both surfaces leads to the prominent $\mathrm{G}$ band at $1580 \mathrm{~cm}^{-1}$ and disorder-induced $\mathrm{D}$ band located at $1310 \mathrm{~cm}^{-1}$. The detection of the $\mathrm{G}$ band has been attributed to the infinitely extended hexagonal symmetry of graphite planes while the discontinuity of these graphite planes that exist at their edge planes leads to the appearance of $\mathrm{D}$ band. ${ }^{41}$ The intensity ratio of the $\mathrm{D}$ band against
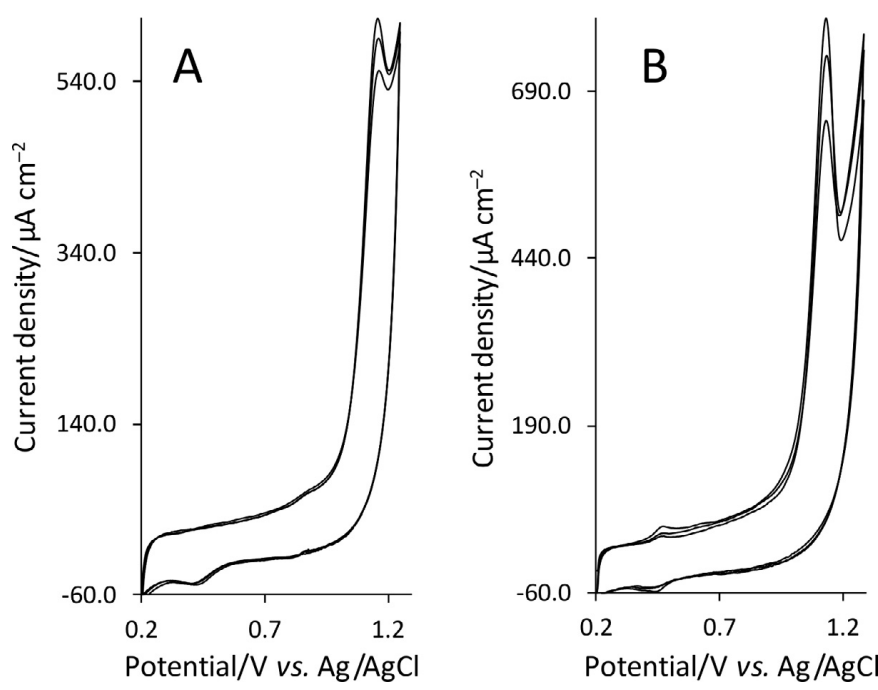

Figure 5 Cyclic voltammograms recorded in $15 \mu \mathrm{M}$ pantoprazole in $0.1 \mathrm{M}$ BRS ( $\mathrm{pH}$ 5) at (A) the anodized EPPG electrode and (B) CNTmodified GC electrode (from top to bottom: first, third and seventh voltammogram). The current values are normalized by the geometric surface area of the electrodes, mentioned in the experimental section. Scan rate $100 \mathrm{mV} \mathrm{s}^{-1}$. 


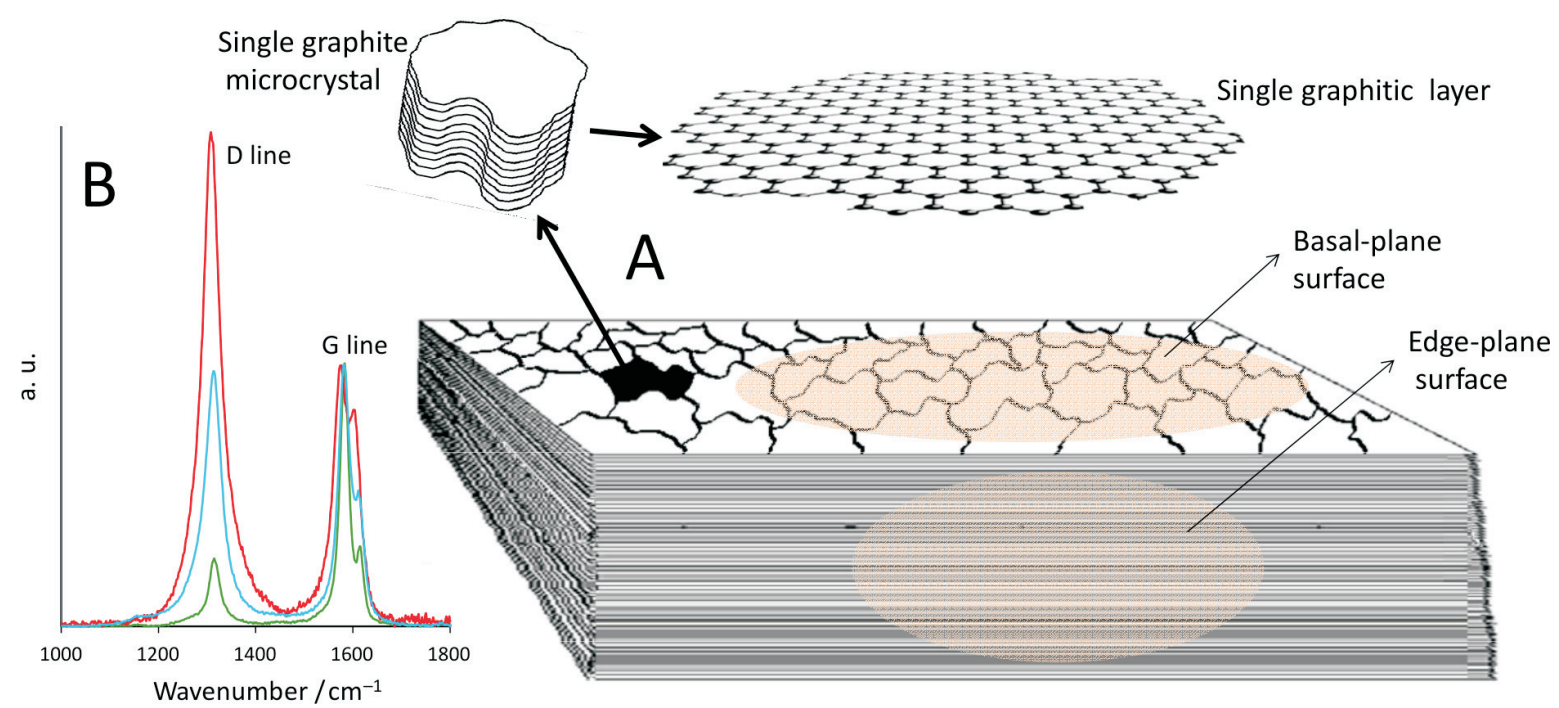

Figure 6 (A) Schematic representation of the pyrolytic graphite microstructure. (B) Raman spectra of the pyrolytic graphite from the (green line) basal-plane surface, (blue line) edge-plane surface before anodization, and (red line) edge-plane surface after anodization.

the $\mathrm{G}$ band, as expected, is larger in the edge-plane than in the basal-plane. This is also in agreement with several reported studies on Raman spectra of pyrolytic graphite. ${ }^{42-44}$ As shown in Fig. 6, the anodization induces a significant increase in the D to G band ratio for the edge-plane surface. In Ref.[43], an increase in the intensity ratio of $\mathrm{D}$ to $\mathrm{G}$ band has been also observed after heat treatment of the polished edge-plane surface in air and has been attributed to the oxidative removal of the surface contaminants of disordered graphitic layers caused by polishing. The surface contamination with disordered graphitic layers or graphite particles in the polishing debris makes it to take some distance from an ideal edge-plane surface (as shown in the schematic illustration in Fig. 6) and to approach, to some extent, to the basal-plane characteristics. Therefore, it can be concluded from these results that, in addition to the effects of generated surface oxide functionalities, the significant enhancement in the electron-transfer activity of the EPPG after anodic activation, could be attributed also to the cleaning effects of anodization.

The potential applied in anodic activation $(1.8 \mathrm{v} v \mathrm{~s} . \mathrm{Ag} / \mathrm{AgCl})$ is sufficiently positive to induce oxygen evolution and to obtain the electrode surface covered with a thin film of oxide functionalities, which can mechanically remove the physically adhered graphitic layers or the residual particles generated by polishing.

\subsection{Analytical Applications}

\subsubsection{Optimization of Some Operational Parameters}

The effect of $\mathrm{pH}$ on the oxidation of pantoprazole at the anodized EPPG electrode was studied. At the $\mathrm{pH}$ values lower than 3, not well-defined peak shapes were observed. In the $\mathrm{pH}$ range $3-5$, as it is clear from Fig. 7, the $I_{\mathrm{p}}$ is not very sensitive to $\mathrm{pH}$ changes but at the $\mathrm{pH}$ values higher than 5 , the $I_{\mathrm{p}}$ decreases significantly.

As the best peak shape was obtained at pH 5 (Fig. 7), all measurements were conducted at this $\mathrm{pH}$. The effect of accumulation time and potential on the electrode response was also examined. It was found that accumulation time of $120 \mathrm{~s}$, during which the solution is stirred at $500 \mathrm{rpm}$, is sufficient to achieve the maximum peak current, the electrode surface becomes saturated with pantoprazole molecules. When equilibration potential was varied from -0.2 to $0.7 \mathrm{~V}$, no significant difference in $I_{\mathrm{p}}$ was found, so, $0.0 \mathrm{~V}$ was chosen as the accumulation potential for all measurements.

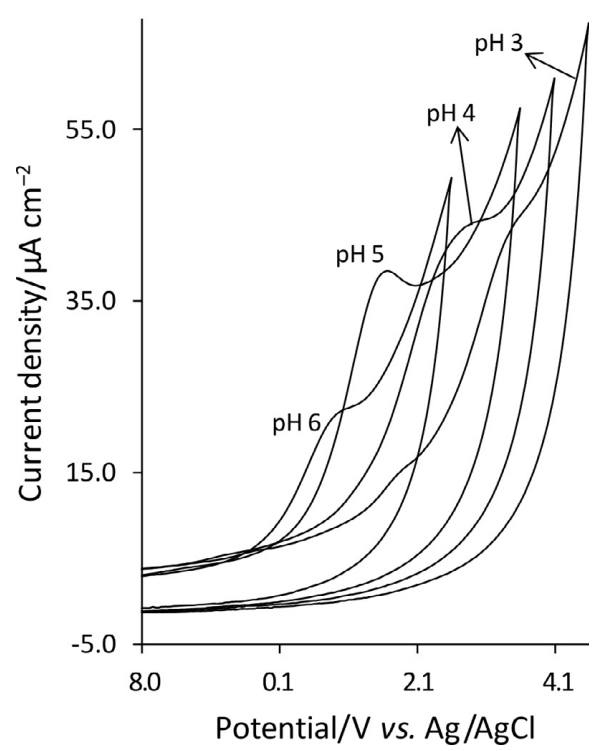

Figure 7 Cyclic voltammograms at the anodized EPPG electrode at the scan rate of $100 \mathrm{mV} \mathrm{s}^{-1}$ in $12 \mu \mathrm{M}$ pantoprazole in $0.1 \mathrm{MBRS}$ at different $\mathrm{pH}$ values.

\subsubsection{Calibration Curve}

Figure 8 shows the cyclic voltammograms for pantoprazole at various concentrations. The $I_{\mathrm{p}}$ values are reported as an average of at least three replicate determinations and the plot of $I_{\mathrm{p}}$ against concentration of pantoprazole (Fig. 8, inset plot A) shows a linear dynamic range of $0.2-25 \mu \mathrm{M}\left(86.5-10800 \mu \mathrm{g} \mathrm{L}^{-1}\right)$. The sensitivity of the proposed method was found to be $3.31 \mu \mathrm{M}^{-1}$. The detection limit of pantoprazole was calculated by using the formula $3 \delta / \mathrm{b}$, where $\delta$ is the standard deviation of the blank and $\mathrm{b}$ is the slope of the calibration curve and has been found to be $0.055 \mu \mathrm{M}$ $\left(23.8 \mu \mathrm{g} \mathrm{L}^{-1}\right)$. Results from pharmacokinetic studies of pantoprazole are indications of the mean values of plasma concentration from about $10000 \mu \mathrm{g} \mathrm{L}^{-1}$ to below $10 \mu \mathrm{g} \mathrm{L}^{-1}$ at about $10 \mathrm{~h}$ after oral or intravenous administration to human volunteers. ${ }^{45,46}$ Most of the upper part of this range can be covered reliably by the linear concentration range obtained with the presented method.

Differential pulse voltammetry (DPV) technique was also used to achieve a lower linear range of concentration. Fig. 9 shows the differential pulse voltammograms for pantoprazole at various 


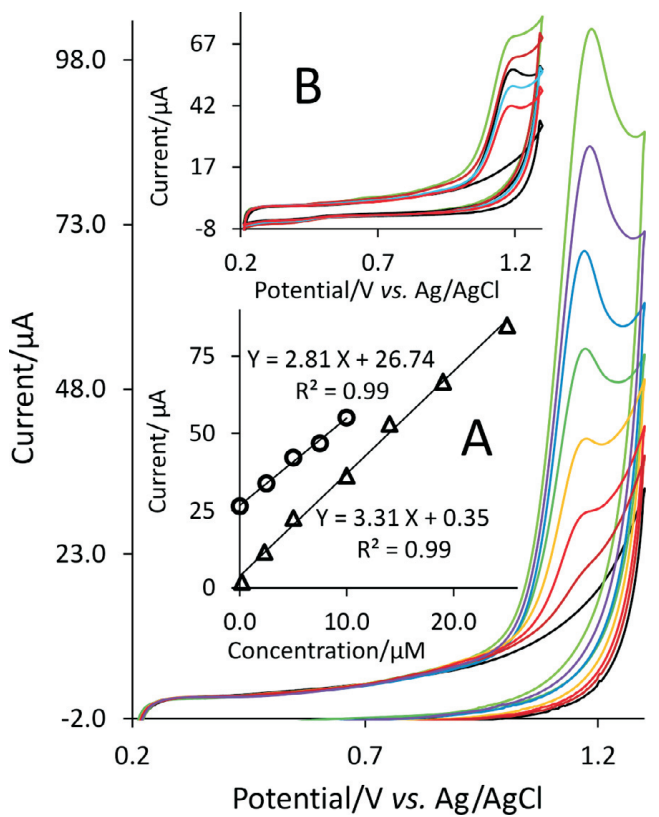

Figure 8 Dependence of the cyclic voltammetric response at the anodized EPPG electrode on pantoprazole concentration in $0.1 \mathrm{M}$ BRS ( $\mathrm{pH} 5$ ) at $100 \mathrm{mV} \mathrm{s}^{-1}$. The corresponding calibration graph $(\triangle)$ is shown in inset A. Concentrations from bottom to top are $0.00,0.20,2.30,5.00,10.00$, $14.00,19.00$ and $25.00 \mu \mathrm{M}$. Inset B shows typical cyclic voltammograms from standard additions of pantoprazole in a pantoprazole solution of Pantomid $^{\circledast}$ (Tehran Chemie Pharmaceutical Co., Tehran, Iran) and the corresponding standard addition calibration graph is shown in inset A $(\bigcirc)$. Each data point in inset $A$ is the mean of at least three replicate determinations.

concentrations. The corresponding calibration plot (inset A of Fig. 9) shows a linear concentration range of $0.02-8.5 \mu \mathrm{M}$ (8.65-3675 $\left.\mu \mathrm{g} \mathrm{L}^{-1}\right)$. The sensitivity was found to be $2.65 \mu \mathrm{A} \mu \mathrm{M}^{-1}$ and the detection limit of the method was calculated to be $4.1 \mathrm{nM}$ $\left(1.8 \mu \mathrm{g} \mathrm{L}^{-1}\right)$ with the signal-to-noise ratio of 3 . The linear concentration range obtained with DPV method can reliably cover the lower part of the concentration range of pantoprazole in plasma reported in the published pharmacokinetic studies. ${ }^{45,46}$

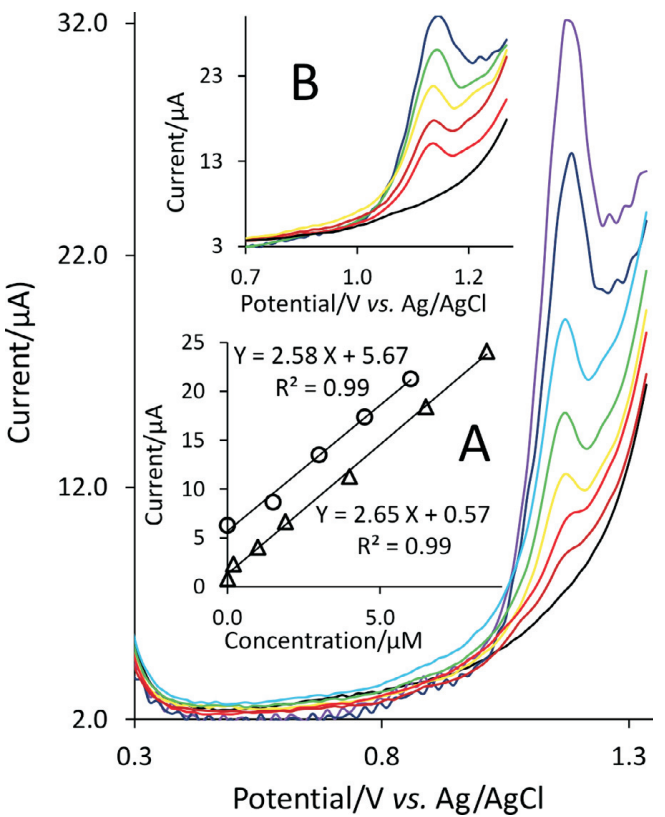

Figure 9 Dependence of the DPV response at the anodized EPPG electrode on pantoprazole concentration in 0.1 M BRS ( $\mathrm{pH} 5$ ). Concentrations from bottom to top are $0.00,0.01,0.20,1.00,1.90,4.00,6.50$ and $8.50 \mu \mathrm{M}$. Inset A shows the corresponding calibration graph $(\triangle)$. Inset $B$ shows typical DPV response from standard additions of pantoprazole in spiked human urine sample solutions and the corresponding standard addition calibration graph is shown in inset $A(O)$. Each data point in inset $\mathrm{A}$ is the mean of at least five replicate determinations.

\subsubsection{Comparison of the Developed Method with Other \\ Electrochemical-based Methods}

The comparison between the analytical performance of the proposed method and other electrochemical methods for the determination of pantoprazole is summarized in Table 2 . Compared with the hanging mercury drop (HMD) electrode, the anodized EPPG electrode shows lower performance in terms of sensitivity and detection limit but in addition to toxicity related problems, the HMD electrode shows a very narrow range of linear concentration. ${ }^{26,27}$

Table 2 Comparison of the proposed voltammetric method with the previously reported electrochemical methods for determination of pantoprazole.

\begin{tabular}{|c|c|c|c|c|c|}
\hline Electrode & Technique & $\begin{array}{l}\text { Linear dynamic range } \\
\qquad / \mu \mathrm{M}\end{array}$ & $\begin{array}{l}\mathrm{LOD} \\
/ \mu \mathrm{M}\end{array}$ & $\begin{array}{l}\text { Sensitivity } \\
\qquad / \mu \mathrm{A} / \mu \mathrm{M}\end{array}$ & References \\
\hline $\mathrm{CP}$ & DPV & $0.1-10$ & 0.02 & 0.2 & 23 \\
\hline GC & DPV & $6-800$ & 0.4 & 0.0238 & 24 \\
\hline GC & $\begin{array}{l}\text { DPV } \\
\text { Square wave voltammetry (SWV) }\end{array}$ & $\begin{array}{l}0.5-7.5 \\
0.675-4.375\end{array}$ & $\begin{array}{l}0.0318 \\
0.0076\end{array}$ & $\begin{array}{l}0.0698 \\
3.5279\end{array}$ & 25 \\
\hline HMD & SWV & $0.35-58$ & 0.11 & 0.028 & 26 \\
\hline HMD & SWV & $0.001-0.05$ & 0.0005 & 28.33 & 27 \\
\hline Sb film plated GC & SWV & $9-200$ & 0.91 & 0.039 & 28 \\
\hline $\begin{array}{l}\text { Pantoprazole anions-doped polypyrrole } \\
\text { film on graphite pencil }\end{array}$ & Potentiometric & $10-11000$ & 6.9 & - & 29 \\
\hline $\begin{array}{l}\text { Molecularly imprinted Polypyrrole/ } \\
\text { multi-walled carbon nanotube-modified } \\
\text { graphite pencil }\end{array}$ & DPV & $5-700$ & 0.375 & - & 30 \\
\hline $\begin{array}{l}\text { Polyvinyl chloride/tetraheptylammonium } \\
\text { bromide (as an anion exchanger) membrane }\end{array}$ & Potentiometric & 10-10000 & 3.98 & - & 31 \\
\hline $\mathrm{NiO}$ nanoparticles-modified GC & Hydrodynamic amperometry & $2.5-180$ & 0.2 & 0.0392 & 32 \\
\hline Anodized EPPG & $\begin{array}{l}\text { CV } \\
\text { DPV }\end{array}$ & $\begin{array}{l}0.2-25 \mu \mathrm{M} \\
0.02-8.5 \mu \mathrm{M}\end{array}$ & $\begin{aligned} 0.055 \\
0.0041\end{aligned}$ & $\begin{array}{l}3.31 \\
2.65\end{array}$ & This work \\
\hline
\end{tabular}


The results in Table 2 also demonstrate that the anodized EPPG has a better response characteristics compared with the other carbon-based electrodes $\left(\mathrm{CP}^{23}\right.$ and $\left.\mathrm{GC}^{24,25}\right)$. Compared with the chemically modified electrodes, ${ }^{28-32}$ the EPPG electrode exhibited a higher analytical performance especially in terms of detection limit and sensitivity (Table 2). These results indicate that by carefully selecting the best electrode among different available carbon-based structures, it is possible to develop a simple analytical method based on direct electro-oxidation of analyte molecules on the electrode surface and to achieve analytical performance comparable or even better than the methods based on time-consuming and complicated electrode surface modification procedures by metals, ${ }^{28}$ metal oxides, ${ }^{32}$ or polymers. ${ }^{29-31}$

\subsubsection{Pantoprazole in Tablets}

To demonstrate the applicability of the proposed method, the anodized EPPG electrode was used to determine the content of pantoprazole in a sample of pharmaceutical formulation, Pantomid $^{\circledR}$ (Tehran Chemie Pharmaceutical Co., Tehran, Iran), using the standard addition method. Some tablets were powdered and homogenized and dissolved into BRS ( $\mathrm{pH} 5$ ). Solutions obtained were filtered to remove the insoluble particulates and then diluted by BRS ( $\mathrm{pH} 5$ ) so that the concentration lay within the range of the calibration curve. Fig. 8 (inset B) shows the standard addition voltammograms and the corresponding standard addition curve are shown in the inset A of this figure. From the analysis of five replicates, the amount of pantoprazole was found to be $38.2( \pm 1.5) \mathrm{mg} \mathrm{tablet}^{-1}(n=5)$, agreeing well with the manufacturer's quoted values of $40 \mathrm{mg}$ tablet $^{-1}$. The low percentage relative errors of only $-4.5 \%(n=5)$ indicate high specificity and accuracy of the proposed method. In addition to pantoprazole as the active ingredient, composition of tablets includes also inactive excipients such as calcium stearate, crospovidone, hypromellose, mannitol, povidone, propylene glycol, sodium carbonate, sodium lauryl sulfate, titanium dioxide, triethyl citrate, and other ingredients. The characteristics of the calibration curve obtained with the synthetic samples of pantoprazole are greatly the same as those obtained with pure pantoprazole (Fig. 8, inset A), which indicate that the procedure is able to assay pantoprazole in the presence of tablet excipients without significant interference problem. Also, the influences of some foreign species that may exist commonly in pharmaceuticals samples on the determination of pantoprazole were investigated. It was found that the glucose, malt sugar, sucrose, fructose and dextrin have no influence on the determination of pantoprazole.

\subsubsection{Interference Study}

In order to estimate if pantoprazole concentration can be analyzed accurately in the presence of some electroactive concomitant substances affecting the selectivity of the proposed method, the influence of ascorbic acid (AA), uric acid (UA) and dopamine (DA), which possibly can occur in some biological fluids, was also tested. The well-defined peak of pantoprazole can be observed from the voltammograms in Fig. 10, which is obtained in the solutions of AA $(100 \mu \mathrm{M})$, UA $(5 \mu \mathrm{M})$ and DA $(5 \mu \mathrm{M})$ spiked with known concentrations of pantoprazole (3 and $5 \mu \mathrm{M}$ ). The analytical determination of pantoprazole in this solution was performed using the calibration curve method and the resulting recovery values were $93.3 \%( \pm 4.1)$ and $95.3 \%$ $( \pm 3.4)$ for 3 and $5 \mu \mathrm{M}$ of pantoprazole, respectively. This indicates that the above compounds did not interfere with the determination of pantoprazole and the presence of these compounds has little influence on the pantoprazole electro-oxidation.

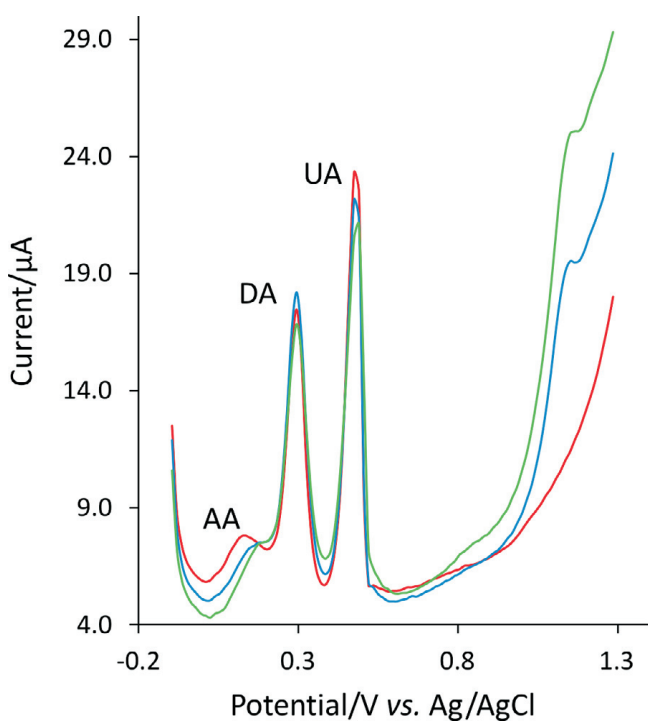

Figure 10 The differential pulse voltammograms recorded the anodized EPPG electrode in a solution containing (red line) AA (50 $\mu \mathrm{M}), \mathrm{DA}$ $(3 \mu \mathrm{M})$ and UA $(10 \mu \mathrm{M})$, in $0.1 \mathrm{M}$ BRS ( $\mathrm{pH} 5)$ and after addition of $3 \mu \mathrm{M}$ (blue line) and $5 \mu \mathrm{M}$ (green line) of pantoprazole.

\subsubsection{Spiked Urine Samples}

The feasibility of anodized EPPG electrode was further assessed for the quantification of pantoprazole in a spiked urine sample. Prior to measurements, samples were diluted with BRS ( $\mathrm{pH} 5$ ). The standard addition method was performed for testing recovery. Typical differential pulse voltammograms are depicted in Fig. 9 (inset B) and the corresponding standard addition line is shown in the inset $A$ of this figure. The slope of this line is only a slightly lower than that of the calibration line obtained for the pure drug in the absence of any complex matrix materials (inset A of Fig. 9). Measurements were repeated five times and the average percent recovery of $97.5 \%( \pm 3.2)$ obtained shows the validity of the method for determination of pantoprazole in real complex matrix samples.

\subsection{Comparison of the Proposed Method with Spectroscopic- based or Chromatographic-based Methods}

To compare the analytical performance of the proposed method with other analytical methods such as spectroscopicbased or chromatographic-based methods, some published papers are considered and listed in Table 3. Although the upper part of linear concentration range of the proposed methods in many cases is lower than those of the tabulated methods, it is high enough for the quantitative determination of pantoprazole in its pharmaceutical dosage form simply by CV technique. Also, in many cases, the detection limit and the lower part of the linear range of the presented method is lower than the other methods in Table 3, which is appropriate for the determination of pantoprazole in plasma or urine samples for clinical studies by DPV technique. These results indicate that the accessible operational concentration range of the presented method is satisfactory. It should also be noted that the main advantageous of the electrochemistry-based methods over spectrophotometric-based or chromatographic-based methods are simplicity, low operating cost, rapid analysis time and portability.

\section{Conclusions}

In the first parts of this paper, the results of direct electrooxidation of pantoprazole at different conventional and nanostructured graphitic carbon-based electrode were investigated in order to develop a sensitive, simple and fast voltammetric 
Table 3 Comparison of analytical data for pantoprazole determination.

\begin{tabular}{|c|c|c|c|}
\hline Method & $\begin{array}{l}\text { Linear dynamic range } \\
\qquad / \mu \mathrm{g} \mathrm{L}^{-1}\end{array}$ & $\begin{array}{l}\mathrm{LOD} \\
/ \mu \mathrm{g} \mathrm{L}^{-1}\end{array}$ & References \\
\hline High performance liquid chromatography (HPLC) & $160000-480000$ & 195.8 & 2 \\
\hline HPLC & $20-5000$ & - & 3 \\
\hline HPLC & $98-25000$ & 2.4 & 4 \\
\hline HPLC & $1000-10000$ & 3 & 5 \\
\hline HPLC & 1000-300000 & 300 & 6 \\
\hline HPLC & $3060-1243000$ & 780 & 7 \\
\hline Chiral liquid chromatography-tandem mass spectrometry & $20-10000$ & - & 8 \\
\hline Liquid chromatography-tandem mass spectrometry & $1-100$ & - & 9 \\
\hline Liquid chromatography-tandem mass spectrometry & $10.00-3000.00$ & - & 10 \\
\hline Achiral-chiral chromatography ion trap mass spectrometry & $0.600-38.4$ & 0.2 & 11 \\
\hline Spectrophotometric & $8000-44000$ & - & 12 \\
\hline Spectrophotometric & $30000-300000$ & 3650 & 13 \\
\hline Spectrophotometric & $500-3500$ & 35 & 14 \\
\hline Spectrophotometric & $250-4000$ & 40 & 15 \\
\hline $\mathrm{CV}$ & $86.5-10800$ & 23.8 & \\
\hline DPV & $8.65-3675$ & 1.8 & This work \\
\hline
\end{tabular}

method for its analysis. It was found that EPPG, after a simple and rapid anodization treatment, shows exceptional performances compared with the other electrodes investigated. The anodization treatment showed a significant enhancing effect on the electrode response due to enrichment in the surface oxides that can promote the electron transfer by acting as the sites for adsorption or accumulation of analyte molecules but the results from Raman spectroscopy analysis indicated that this enhancing influence can be also attributed to the cleaning effect of anodization.

As a matter of fact, as there are numerous reports in the current literature that recommend the use of nanostructured carbon (such as CNT and nanographenes) as preferred materials in electrochemical sensing applications, one might perhaps at the first glance have expected greater electrode performances for the CNT or ErGO electrodes in the electro-oxidation of pantoprazole but the results in this study indicates, at least, that a preliminary investigation of different carbon-based materials should be a useful attempt to achieve as better analysis results as possible. In the last parts of this paper, the quantitative analysis of pantoprazole in medicinal samples was carried out using the proposed method with satisfactory results as the detected content was in good agreement with the reported values. Also, the practical utility of the method was successfully examined by analyzing spiked urine samples. Owing to simplicity, rapidity and low cost of analysis, this method, based on the anodized EPPG electrode, may be used as a promising alternative to the reported chromatographic or spectroscopic methods.

\section{Acknowledgements}

The authors gratefully acknowledges Iran Carbon Co. (Tehran, Iran) for supplying CB sample.

\section{References}

1 A. Dettmer, R. Vogt, F. Sielaff, R. Luhmann, A. Schneider and R. Fischer, Pantoprazole $20 \mathrm{mg}$ is effective for relief of symptoms and healing of lesions in mild reflux oesophagitis, Aliment. Pharmacol. Ther., 1998, 12, 865-872.

2 B. Siddartha and I.S. Babu, Analytical method development and method validation for the estimation of pantoprazole in tablet dosage form by RP-HPLC, Der Pharma. Chemica., 2013, 5, 99-104.

3 N.V.S. Ramakrishna, K.N. Vishwottam, S. Wishu and M. Koteshwara, High-performance liquid chromatography method for the quantification of pantoprazole in human plasma, J. Chromatogr., B 2005, 822, 326-329.
4 P.R. Battu and N.K.K. Reddy, Development and validation of RPHPLC for the pantoprazole sodium sesquihydrate in pharmaceutical dosage forms and human plasma, Int. J. ChemTech. Res., 2009, 1, 195-198.

5 T. Sivakumar, R. Manavalan and K. Valliappan, Development and validation of a reversed-phase HPLC method for simultaneous determination of domperidone and pantoprazole in pharmaceutical dosage forms, Acta Chromatogr., 2007, 18, 130-142.

6 S.S. Perumal, S.P. Ekambaram and S. Raja, Analytical method development and validation of simultaneous estimation of rabeprazole, pantoprazole, and itopride by reverse-phase high-performance liquid chromatography, J. Food Drug Anal., 2014, 22, 520-526.

7 S. Ashour and S. Omar, A modified high-performance liquid chromatographic method for the analysis of pantoprazole sodium in pharmaceutical dosage forms using lansoprazole as internal standard, Arabian J. Chem., 2011, In press.

8 M. Chen, Y. Xia, Z. Ma, L. Li, D. Zhong and X. Chen, Validation of a chiral liquid chromatography-tandem mass spectrometry method for the determination of pantoprazole in dog plasma, J. Chromatogr. B, 2012, 906, 85-90.

9 B.L. Bhaskara, U.R. Anil Kumar and K. Basavaiah, Sensitive liquid chromatography-tandem mass spectrometry method for the determination of pantoprazole sodium in human urine, Arabian J. Chem., 2011, 4, 163-168.

10 B.R. Challa, S.H.S. Boddu, B.Z. Awen, B.R. Chandu, C. K. Bannoth, M. Khagga, K. Kanala and R. P. Shaik, Development and validation of a sensitive bioanalytical method for the quantitative estimation of Pantoprazole in human plasma samples by LC-MS/MS: application to bioequivalence study, J. Chromatogr. B, 2010, 878, 1499-1505.

11 J.C. Barreiro, K.L. Vanzolini and Q.B. Cass, Direct injection of native aqueous matrices by achiral-chiral chromatography ion trap mass spectrometry for simultaneous quantification of pantoprazole and lansoprazole enantiomers fractions, J. Chromatogr. A, 2011, 1218, 2865-2870.

12 N.K. Ramadan, N.A. El-Ragehy, M.T. Ragab and B.A. El-Zeany, Simultaneous determination of a binary mixture of pantoprazole sodium and itopride hydrochloride by four spectrophotometric methods, Spectrochim. Acta, 2015, 137, 463-470.

13 F. Salama, N. El-Abasawy, S.A. Abdel Razeq, M.M.F. Ismail and M.M. Fouad, Validation of the spectrophotometric determination of omeprazole and pantoprazole sodium via their metal chelates, J. Pharm. Biomed. Anal., 2003, 33, 411-421.

14 A.M. Wahbi, O. Abdel-Razak, A.A. Gazy, H. Mahgoub and M.S. Moneeb, Spectrophotometric determination of omeprazole, lansoprazole and pantoprazole in pharmaceutical formulations, J. Pharm. Biomed. Anal., 2002, 30, 1133-1142.

15 O.Z. Devi and K. Basavaiah, Validated spectrophotometric determination of pantoprazole sodium in pharmaceuticals using ferric chloride and two chelating agents, Int. J. ChemTech. Res., 2010, 2, 624-632. 
16 S. Moane, J.R. Barreira Rodriguez, A.J. Miranda Ordieres, P. Tunon Blanco and M.R. Smyth, Electrochemical behaviour of clenbuterol at Nafion-modified carbon-paste electrodes, J. Pharm. Biomed. Anal., $1995,14,57-63$

17 B. Uslu and S.A. Ozkan, Electroanalytical application of carbon based electrodes to the pharmaceuticals, Anal. Lett., 2007, 40, 817-853.

18 B. Uslu and S.A. Ozkan, Solid electrodes in electroanalytical chemistry: present applications and prospects for high throughput screening of drug compounds, Comb. Chem. High. T. Scr., 2007, 10, 495-513.

19 R.L. McCreery, Advanced carbon electrode materials for molecular electrochemistry, Chem. Rev., 2008, 108, 2646-2687.

20 Y. Shao, J. Wang, H. Wu, J. Liu, I.A. Aksay and Y. Lin, Graphene based electrochemical sensors and biosensors: a review, Electroanalysis, 2010, 22, 1027-1036.

21 G.G. Wallace, J. Chen, D. Li, S.E. Moulton and J.M. Razal, Nanostructured carbon electrodes, J. Mater. Chem., 2010, 20, 3553-3562.

22 R.L. McCreery, in Electroanalytical Chemistry, (A.J. Bard, ed.), Marcel Dekker, New York, 1991.

23 A. Radi, Determination of pantoprazole by adsorptive stripping voltammetry at carbon paste electrode, Il Farmaco, 2003, 58, 535-539.

24 N. Erk, Differential pulse anodic voltammetric determination of pantoprazole in pharmaceutical dosage forms and human plasma using glassy carbon electrode, Anal. Biochem., 2003, 323, 48-53.

25 A.M. Elsied H and G.G. Mohamed, Sensitive electrochemical determination of pantoprazole sodium in pure form pharmaceutical formulations and biological fluid at glassy carbon electrode using differential pulls and square wave techniques, Int. J. Electrochem. Sci, 2015, 10, 7147-7158.

26 S. Altınöz and I. Süslü, Determination of pantoprazole in pharmaceutical formulations and human plasma by square-wave voltammetry, Anal. Lett., 2005, 38, 1389-1404.

27 A. Radi, Square-wave adsorptive cathodic stripping voltammetry of Pantoprazole, J. Pharm. Biomed. Anal., 2003, 33, 687-692.

28 A. Nigovic and S.B. Hocevar, Square-wave voltammetric determination of pantoprazole using ex situ plated antimony-film electrode, Electrochim. Acta, 2013, 109, 818-822.

29 B.V. Noronha, E.H. Bindewald, M.C. de Oliveira, M.A.P. Papi, M.F Bergamini and L.H. Marcolino Jr., Potentiometric determination of pantoprazole using an ion-selective sensor based on polypyrrole doped films, Mater. Sci. Eng. C, 2014, 43, 517-520.

30 A. Nezhadali and R. Shadmehri, Neuro-genetic multi-objective optimization and computer-aided design of pantoprazole molecularly imprinted polypyrrole sensor, Sens. Actuators B, 2014, 202, 240-251.

31 M.T. Ragab, M.K. Abd El-Rahman, N.K. Ramadan, N.A. El-Ragehy and B.A. El-Zeany, Novel potentiometric application for the determi- nation of pantoprazole sodium and itopride hydrochloride in their pure and combined dosage form, Talanta, 2015, 138, 28-35.

32 A. Salimi, Z. Enferadi, A. Noorbakhash and K. Rashidi, Sensitive amperometric detection of omeprazole and pantoperazole at electrodeposited nickel oxide nanoparticles modified glassy carbon electrode, J. Solid State Electrochem., 2012, 16, 1369-1375.

33 C.E. Banks and R.G. Compton, Edge plane pyrolytic graphite electrodes in electroanalysis: an overview, Anal. Sci., 2005, 21,1263-1268.

34 C.E. Banks and R.G. Compton, New electrodes for old: from carbon nanotubes to edge plane pyrolytic graphite, Analyst, 2006,131,15-21.

35 R.L. McCreery, in Interfacial Electrochemistry, (A. Wieckowski, Ed), Marcel Dekker, New York, 1999.

36 J.F. Wang, S.L. Yang, D.Y. Guo, P. Yu, D. Li, J. S. Ye and L.Q. Mao, Comparative studies on electrochemical activity of graphene nanosheets and carbon nanotubes, Electrochem. Commun., 2009, 11, 1892-1895.

37 L.H. Tang, Y. Wang, Y. M. Li, H.B. Feng, J. Lu and J.H. Li, Preparation, structure, and electrochemical properties of reduced graphene sheet films, Adv. Funct. Mater., 2009, 19, 2782-2789.

38 C.H.A. Wong, A. Ambrosi and M. Pumera, Thermally reduced graphenes exhibiting a close relationship to amorphous Carbon, Nanoscale, 2012, 4, 4972-4977.

39 R.R. Moore, C.E. Banks and R.G. Compton, Basal plane pyrolytic graphite modified electrodes: comparison of carbon nanotubes and graphite powder as electrocatalysts, Anal. Chem., 2004, 76, 2677-2682.

40 M.S. Goh and M. Pumera, Single-, few-, and multilayer graphene not exhibiting significant advantages over graphite microparticles in electroanalysis, Anal. Chem., 2010, 82, 8367-8370.

41 Y. Wang, D.C. Alsmeyer and R.L. McCreery, Raman spectroscopy of carbon materials: structural basis of observed spectra, Chem. Mater. 1990, 2, 557-563.

42 K. Ray and R.L. McCreery, Spatially resolved Raman spectroscopy of carbon electrode surfaces: observations of structural and chemical heterogeneity, Anal. Chem., 1997, 69, 4680-4687.

43 G. Katagiri, H. Ishida and A. Ishitani, Raman spectra of graphite edge planes, Carbon, 1988, 26, 565-571.

44 G. Compagnini, O. Puglisi and G. Foti, Raman spectra of virgin and damaged graphite edge planes, Carbon, 1997, 35, 1793-1797.

45 V. Kliem, J. Bahlmann, M. Hartmann, R. Huber and R. Luhmann, W. Wurst, Pharmacokinetics of pantoprazole in patients with end-stage renal failure, Nephrol. Dial. Transplant., 1998, 13, 1189-1193.

46 Y. Li, M. Ding, J. Ma, S. Wang, X. Wu, H. Xu, Z. Lu, J. Zou, H. Fan and X. Zhou, Quantification of pantoprazole in human plasma using LC-MS/MS for pharmacokinetics and bioequivalence study, Eur. J. Drug Metab. Pharmacokinet., 2011, 35, 147-155. 